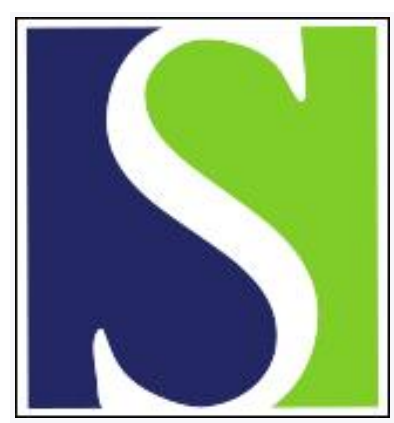

Scand J Work Environ Health 1986;12(4):413-416

https://doi.org/10.5271/sjweh.2121

Issue date: Aug 1986

Responses of mechanoreceptive afferent units in the glabrous skin of the human hand to vibration.

by Lundstrom RJ

This article in PubMed: www.ncbi.nlm.nih.gov/pubmed/3775331

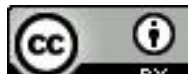




\title{
Responses of mechanoreceptive afferent units in the glabrous skin of the human hand to vibration
}

\author{
by Ronnie JI Lundström, DrMedSc ${ }^{1}$
}

\begin{abstract}
LUNDSTRÖM RJI. Responses of mechanoreceptive afferent units in the glabrous skin of the human hand to vibration. Scand J Work Environ Health 12 (1986) 413-416. The impulse response to vibration $(0.5-400 \mathrm{~Hz}, 0.001-1.0 \mathrm{~mm})$ was recorded from single mechanoreceptive afferents innervating the glabrous skin of the human hand. Needle electrodes inserted into the median nerve were used for the recording. The four types of mechanoreceptive afferents (FA I, FA II, SA I, and SA II) exhibited different response characteristics. Fast adapting units were the most easily excited at frequencies between about 5 to $50 \mathrm{~Hz}$ (FA I) and above about $50 \mathrm{~Hz}$ (FA II). The sensitivity of the slowly adapting units (SA I and SA II) was greatest at lower frequencies. Unit thresholds at 2,20, and $200 \mathrm{~Hz}$ were measured before and after $2 \mathrm{~min}$ of powerful vibration exposure. Corresponding psychophysical thresholds were also measured during the recording of responses from single units. An acute but temporary depression in sensitivity occurred in the FA I, FA II, and SA I units as a consequence of the exposure. The magnitude and the time courses of the recovery of the encountered unit threshold shifts were approximately the same as those for the corresponding psychophysical threshold shifts. It was concluded that acute impairments of the tactile sensibility caused by vibration exposure, as observed in psychophysical studies, can probably be explained by an influence on the excitability of the tactile units.
\end{abstract}

Key terms: hand, mechanoreceptors, sensibility, skin, tactile perception, vibration.

With the introduction of the microneurographic method for recording impulses from single afferent nerve fibers in awake human subjects, it became possible to study the peripheral tactile neuronal mechanism in man. This method also provided the possibility to combine neurophysiological and psychophysical responses directly. After Knibestöl \& Vallbo (3) first explored tactile units in the glabrous skin of the human hand using this technique, several investigations of the functional properties of these units have been carried out. (For a review, see reference 2.)

There are about 17000 mechanoreceptive units of four different types innervating the glabrous skin area of the hand. They have been classified into two major categories on the basis of their adaptation and receptive field properties (figure 1). Two types are fast adapting (FA I and FA II) and respond only when the skin is in motion. The other two types are slowly adapting (SA I and SA II units). They are sensitive to moving stimuli, but they also exhibit a response related to the amplitude of a constant deformation of the skin. Type I units are characterized by small and well defined receptive fields. In contrast, type II units have larger receptive fields with obscure borders. Some characteristic features of the FA II and SA II units are sensitivity to remote mechanical transients and sensitivity to remote lateral skin stretch, respectively.

\footnotetext{
1 National Board of Occupational Safety and Health, Umeå, Sweden.

Reprint requests to: Dr RJI Lundström, National Board of Occupational Safety and Health, Box 6104, S-900 06 Umeå, Sweden.
}

The end organs of the FA I units are probably Meissner's corpuscles located in the dermal papillae. The pacinian corpuscles, located in the deep dermis and subcutaneous tissues and the smaller and simpler lamellated Golgi-Mazzoni bodies in the dermis are probably the endings of the FA II units. The endings of the SA I units are Merkel's cell neurite complexes located at the tip of the intermediate epidermal ridges. Finally, the SA II units probably terminate with the spindle shaped Ruffini endings located in the dermis.

During the use of a vibrating hand-held tool a very accurate and close interplay between sensory and motor control of the hand has to exist. A key role in providing the central nervous system with information of mechanical events is played by the population of mechanoreceptive afferent units innervating the glabrous skin in contact with the vibrating handle. It is known that an acute reduction in tactile sensibility appears during, and for a time after, exposure to vibration (4). For persons with a previous history of work with vibrating tools, permanent impairment has also been shown (4). Yet very little is known as to the mechanism behind these effects.

The purpose of the present experiments was to investigate (i) the responses of tactile afferent units innervating the glabrous skin of the human hand to vibration with different frequencies and amplitudes and (ii) the temporary reduction in sensitivity occurring among cutaneous mechanoreceptors after a powerful vibration exposure and its relation to psychophysical observations. 


\section{Methods}

\section{Subjects, procedure and apparatus}

Experiments were carried out on healthy adult human subjects, none of whom had been engaged in heavy manual work or work with vibrating tools. The subjects sat comfortably in a dentist's chair with their right arm extended laterally and supported by a vacuum cast. To avoid movements, the dorsum of the hand was embedded in a Plasticine (Colman) mold, and finger clamps were occasionally used for additional fixation.

Nerve impulses in single afferent mechanoreceptive units were recorded with tungsten needle electrodes inserted percutaneously into the median nerve about 10

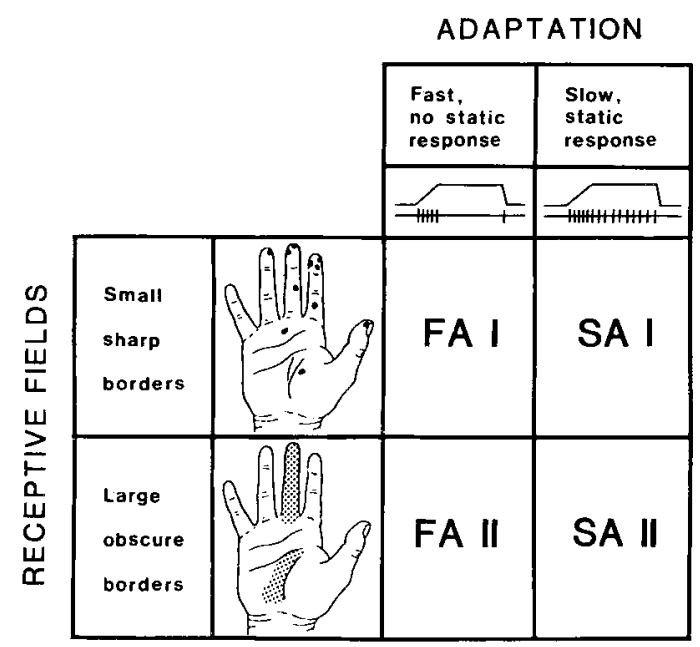

Figure 1. Types of mechanoreceptive afferent units in the glabrous skin of the human hand, classified on the basis of their adaptation and receptive field properties. The graphs in the upper right-hand corner show the impulse discharge (lower line) to ramp indentations of the skin (upper line). The darkened areas of the drawings show the extent of the typical receptive fields (reprinted from reference 5 with the permission of the publisher).

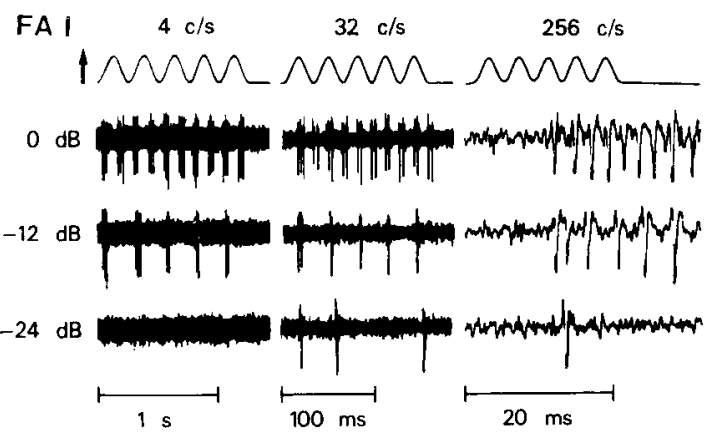

Figure 2. Examples of discharge patterns of an individual unit (FA I) at three different amplitudes and three different frequencies. The uppermost row shows the time course of the vibration which was superimposed on a $0.5-\mathrm{mm}$ preindentation. The arrow indicates the direction of skin indentation. The lowe rows show neuronal impulse discharges. Each column refers to a single stimulus frequency and each row to a constant amplitude given in decibels [rel $1 \mathrm{~mm}$ (peak to peak)]. (c = cycle, rel $=$ relative . $\mathrm{cm}$ proximal to the elbow $(1,3,5,6,7)$. The recording electrode was then adjusted manually in small steps until the activity from a single unit could be distinguished from the background activity of the nerve fascicle.

After isolation and classification of the unit in accordance with the described criteria, sinusoidal skin displacements were delivered through a small perspex probe (diameter $6-8 \mathrm{~mm}$ ) driven by a feedback moving coil stimulator whose main electrical and mechanical functions have been described elsewhere (10). A set of computer-controlled test sequences, consisting of sinusoidal vibration with different frequencies $(0.5-400 \mathrm{~Hz})$, amplitudes $[0.001-1 \mathrm{~mm}$, peak to peak (p-p)], and durations (up to $2 \mathrm{~min}$ ) were executed. A static preindentation of $0.5-1 \mathrm{~mm}$ was used to obtain a stable mechanical coupling between the skin and the probe.

\section{Neuronal response measurements}

The test stimuli were delivered as a sequence of sinewave bursts, each consisting of five sine-wave cycles. A test sequence consisted of a series of consecutive bursts of constant amplitude but of 11 different frequencies between 0.5 and $400 \mathrm{~Hz}$. The amplitude was varied between test sequences, starting with $1 \mathrm{~mm}(\mathrm{p}-\mathrm{p})$. The amplitude was attenuated stepwise by $6-8 \mathrm{~dB}$ until the unit did not respond to any of the frequencies in the test sequence. The neuronal discharges were recorded, together with the signals describing the probe movements (figure 2). The average number of impulses evoked per cycle of the sine-wave bursts was calculated and denoted as the cycle response.

\section{Unit and psychophysical threshold measurements}

The threshold of a tactile unit, as well as the psychophysical threshold, was determined with a modified version of the von Bekesy (8) threshold tracking method. The experimenter or the subject controlled the amplitude by a remote-control push button. The stimulus amplitude gradually declined when the button was pressed and gradually increased when it was released. During the unit threshold measurement, the experimenter pressed the button as soon as the vibration had reached an amplitude evoking one impulse per cycle and released it again as soon as the impulse discharge disappeared. During the psychophysical threshold measurements, the subject was asked to press the control button as soon as the vibration could be perceived and keep it pressed in as long the vibration was still felt.

When a unit had been isolated and classified, a test sequence was executed, including a determination of the unit threshold, followed by a 2 -min vibration exposure and then a new threshold determination that started immediately after the exposure. The post- 
exposure threshold was continuously tracked until no signs of further recovery of sensitivity were observed. After a rest period of $2-3$ min a new test sequence was executed, during which the psychophysical thresholds were determined.

The following three different test frequencies were used: 2, 20, and $200 \mathrm{~Hz}$. The same frequency was always used during the two threshold measurements in the test sequence. The amplitude of the vibration exposure was preset to $1.5,1$, and $0.25 \mathrm{~mm}$ (p-p) at 2,20 , and $200 \mathrm{~Hz}$, respectively.

\section{Results}

\section{Neuronal response to vibration}

It was shown that the cycle response varied with the unit type and the frequency and amplitude of the stimuli (figure 3). The FA II units were the most easily excited at high frequencies, above about $50 \mathrm{~Hz}$. At about $250 \mathrm{~Hz}$ the stimulus amplitude required for evoking a response could be as low as $1 \mu \mathrm{m}$ (p-p). The FA I units were the most easily excited at frequencies between about 5 and $50 \mathrm{~Hz}$, and the lowest amplitude, about $8 \mu \mathrm{m}$ (p-p) for evoking discharges, occurred at about $30 \mathrm{~Hz}$. The SA units were particularly sensitive at lower frequencies (the type I units between about $2-30 \mathrm{~Hz}$ and the SA II below about $8 \mathrm{~Hz}$ ).

As can be seen in the upper part of figure 3 , at high stimulus amplitudes, well above the thresholds of the units, a big overlap existed between the FA I, FA II, and SA I units with regard to the frequency ranges at which they responded. For the FA units the frequency range within which the units could be exited increased rapidly with the stimulus amplitude. Furthermore, as the stimulus amplitude increased, the frequency for the maximal cycle response decreased.

\section{Acute impairment of tactile sensitivity}

The preexposure thresholds for the FA II units were within $2-5 \mu \mathrm{m}(\mathrm{p}-\mathrm{p})$ at $200 \mathrm{~Hz}, 30-70 \mu \mathrm{m}(\mathrm{p}-\mathrm{p})$ at $20 \mathrm{~Hz}$, and about $1 \mathrm{~mm}(\mathrm{p}-\mathrm{p})$ at $2 \mathrm{~Hz}$. At $200 \mathrm{~Hz}$ all FA II units showed a temporary threshold shift of $15-26 \mathrm{~dB}$, if measured $10 \mathrm{~s}$ after the end of exposure. As can be seen in figure 4 , the recovery rate was initially rapid but declined with time. Similar threshold shifts were observed at $20 \mathrm{~Hz}$. As regards the psychophysics, the temporary threshold shifts at $200 \mathrm{~Hz}$ were between 18 and $24 \mathrm{~dB}$, ie, the shifts were similar to those observed with the FA II units. Likewise, the preexposure thresholds and the time courses of the recovery were similar.

The FA I units showed preexposure thresholds of $18-200 \mu \mathrm{m}$ (p-p). Temporary threshold shifts between 3 and $15 \mathrm{~dB}$ were observed at $20 \mathrm{~Hz} 10 \mathrm{~s}$ after the exposure. The strongest shifts were found for the most sensitive units. An exposure with $200 \mathrm{~Hz}$ resulted in smaller threshold shifts (about 2-6 dB) determined at both 20 and $200 \mathrm{~Hz}$. A $2-\mathrm{Hz}$ exposure did not clearly
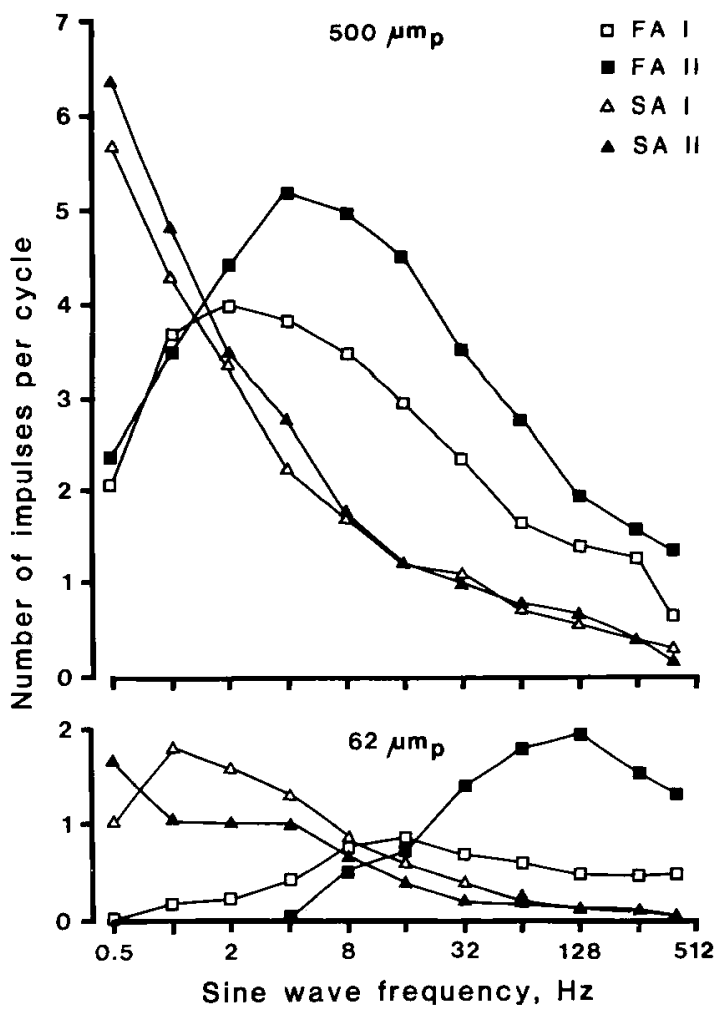

Figure 3. Relation between the frequency of vibration and the average number of impulses per sine-wave cycle for the four types of mechanoreceptive afferent units innervating the glabrous skin of the human hand (8 FA I, 4 FA II, 4 SA I, 8 SA II). The graphs represent two different stimulus amplitudes, 0.5 and $0.062 \mathrm{~mm}$ (peak) (reprinted from reference 5 with the permission of the publisher).

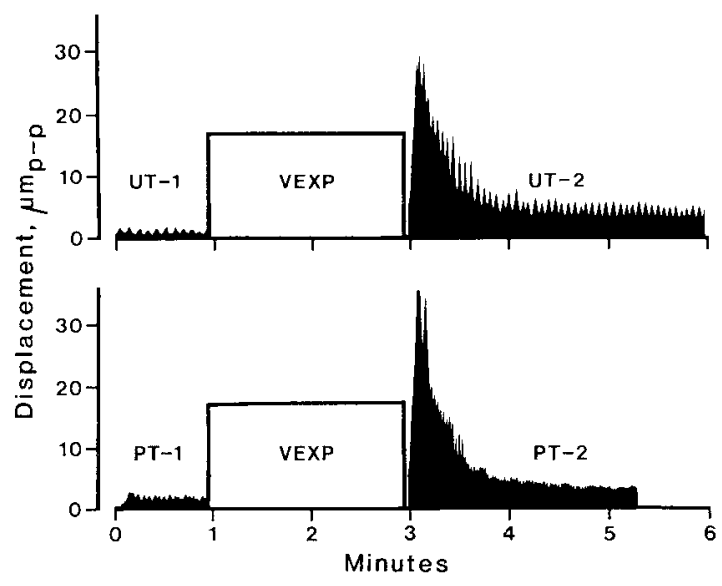

Figure 4. Threshold tracking at $200 \mathrm{~Hz}$ before and after exposure to vibration (VEXP) for a FA II unit (UT-1 and UT-2) and the corresponding psychophysical threshold (PT-1 and PT-2). The vibration exposure [ $200 \mathrm{~Hz}, 0.25 \mathrm{~mm}$ ( $p$-p) during $2 \mathrm{~min}$ ] is schematically indicated by the box between the threshold determinations. For further details, see the text (modified from reference 6$)$. $(p-p=$ peak to peak $)$ 
influence the sensitivity of the FA I units. The corresponding psychophysical threshold shifts at $20 \mathrm{~Hz}$ were between 6 and $12 \mathrm{~dB}$, ie, in the same range as for the most sensitive FA I units.

The preexposure thresholds at $2 \mathrm{~Hz}$ was about 200 $\mu \mathrm{m}(\mathrm{p}-\mathrm{p})$ for most of the SA I units. The vibration exposure caused only a slight depression in sensitivity for some of the units, whereas there was a threshold shift of about 6-9 dB for the others. These units needed about $2 \mathrm{~min}$ to recover. Similar threshold shifts were observed after exposure at $20 \mathrm{~Hz}$. A good correlation was found between the neuronal and psychophysical pre- and postexposure thresholds only for the most sensitive SA units.

The threshold for SA II units, determined at $2 \mathrm{~Hz}$, were between 130 and $255 \mu \mathrm{m}$ (p-p). No convincing influence on the thresholds at $2 \mathrm{~Hz}$ were observed as a result of the exposure at 2,20 , and $200 \mathrm{~Hz}$. No reliable response from these units was observed during the psychophysical threshold measurements.

\section{Discussion}

The present results clearly show that the four types of low threshold mechanoreceptive units in the glabrous skin of the human hand exhibit different response properties to vibration within the frequency range of $0.5-400 \mathrm{~Hz}$. The FA I units appeared to mediate the detection of vibration within the frequency range of 5 to $50 \mathrm{~Hz}$. The FA II units appeared to account for the detection of vibration and mechanical transients of higher frequencies, ie, above $40-50 \mathrm{~Hz}$. The SA units were the most easily excited at frequencies lower than $8-16 \mathrm{~Hz}$. However, psychophysical detection of these low frequencies is probably based on the activity of SA I units.

Due to the considerable overlap of the frequency ranges at which the units responded at higher stimulus amplitudes, it can be inferred that all types of mechanoreceptive afferents will probably be excited during the use of most vibrating tools. Moreover, selective stimulation of a particular type of unit through selection of its "best" frequency is only possible when the stimulus amplitude is close to the absolute threshold of that unit population.

The present results provide clear evidence that the temporary losses in tactile sensibility appearing after exposure to vibration depend to a large extent on a depression of the excitability of the tactile units. The observed depression was temporary, and the rate of recovery was initially rapid, but it gradually declined with time. Moreover, a close correlation was found between the neural and psychophysical thresholds with regard to the magnitude of the shift and the time course of the recovery.

During the depression of the sensibility, occurring both during and after exposure to vibration, the motor skills of the hand may be impaired, and disturbances may occur in the regulation of grip forces (9). This is not only a serious handicap in most activities, but may also imply an increased risk of accidents. Thus the depression of the tactile sensibility that occurs after work with vibrating tools may also account for many acute injuries usually not connected to vibration. This risk may be particularly pronounced during tasks requiring alternations between the use of nonvibrating and vibrating tools.

Most studies concerning vibrotactile threshold measurements have apparantly been limited to frequencies above about $40 \mathrm{~Hz}$, ie, frequencies normally detected by the FA II units. Lower frequencies detected by the other types of tactile units (FA I and SA units) have thus been neglected. Vibrotactile measurements as a diagnostic tool for grading the severity of vibration damage should, according to the present results, include test frequencies which do not focus on the FA II units, ie, they should include frequencies below about $40 \mathrm{~Hz}$ as well.

\section{Acknowledgments}

I wish to thank Drs RS Johansson and U Landström for their cooperation during this study.

The financial support provided by the Swedish Work Environment Fund and the Swedish Medical Research Council is gratefully acknowledged.

\section{References}

1. Johansson RS, Landström U, Lundström R. Responses of mechanoreceptive afferent units in the glabrous skin of the human hand to sinusoidal skin displacement. Brain Res 244 (1982) 17-25.

2. Johansson RS, Vallbo ÅB. Tactile sensory coding in the glabrous skin of the human hand. Trends Neuro Sci 6 (1983) $27-32$.

3. Knibestöl M, Vallbo $\AA$ B. Single unit analysis of mechanoreceptor activity from the human glabrous skin. Acta Physiol Scand 80 (1970) 178-195.

4. Lidström I-M, Hagelthorn G, Bjerker N. Vibration perception in persons not previously exposed to local vibration and in vibration-exposed workers. In: Brammer AJ, Taylor $W$, ed. Vibration effects on the hand and arm in industry. John Wiley \& Sons, New York, NY 1982, pp 59-65.

5. Lundström R. Vibration exposure of the glabrous skin of the human hand. Arbetarskyddsverket, Stockholm 1985. (Arbete \& hälsa 10: 1985).

6. Lundström, R, Johansson RS. Acute impairment of the sensitivity of skin mechanoreceptive units caused by vibration exposure of the hand. Ergonomics 29 (1986) $687-698$.

7. Vallbo $\dot{A} B$, Hagbarth K-E. Activity from skin mechanoreceptors recorded percutaneously in awake human subjects. Exp Neurol 21 (1968) 270-289.

8. von Bekesy G. Über die vibrationsempfindung. Akust Z 4 (1939) 316-334.

9. Westling G, Johansson RS. Factors influencing the force control during precision grip. Exp Brain Res 53 (1984) 277-284.

10. Westling G, Johansson RS, Vallbo ÅB. A method for mechanical stimulation of skin receptors. In: Zotterman $\mathrm{Y}$, ed. Sensory functions of the skin. Pergamon Press, Oxford 1976, pp 151-158. 